\title{
Suicidal ideation in bully victimized school children and adolescents:a meta analysis
}

\author{
Mohammad Kamrul Hassan Shabuj, ${ }^{1}$ Sanjoy Kumer Dey, ${ }^{2}$ Sadeka Chowdhury Moni, ${ }^{1}$ \\ Md Faruk Hossain, ${ }^{3}$ Jesmin Hossain ${ }^{4}$ \\ ${ }^{1}$ Assistant Professor, Department of Neonatology, Bangabandhu Sheikh Mujib Medical University, BSMMU, Dhaka, Bangladesh; \\ ${ }^{2}$ Associate Professor, Department of Neonatology, BSMMU, Dhaka, Bangladesh; ${ }^{3}$ Associate Professor, Department of Psychiatry, \\ Khaja Yunus Ali Medical College, Sirajgonj, Bangladesh; ${ }^{4}$ Asistant Professor, Department of Pediatrics, National Heart Foundation \\ Hospital and Research institute, Mirpur, Dhaka, Bangladesh.
}

Article info

Received

Accepted

Number of tables : 01

Number of figures : 03

Number of refs : 46

\section{Correspondence}

Mohammad Kamrul Hassan Shabuj,

E-mail: Shabuj619@yahoo.com

Phone no: +8801712615427

\begin{abstract}
Summary
In the recent years there has been increased attention to the association of bullying involvement and suicidal ideation in school going children and adolescents. This meta analytic study was conducted by online searching of articles using Pub Med data bases and Google scholar. Total 21 both USA based and non USA based studies were included and sample size were 219,929. We used the research term 'bullying', 'suicide', 'children', 'adolescence', 'school bullying' , 'suicidal ideation' and by using the term 'cross sectional studies', from 2010 to 2013 for studies identification. One predictor bully victimization and one outcome suicidal ideation were analyzed. Inverse weighted average was measured to see the effect size and forest plot was applied for data presentation. All the steps of meta analysis were followed. Our pooled data showed increase risk of suicidal ideation in bully victim. The results showed that odd ratio of suicidal ideation was 2.18 in bully victims in USA based studies and $95 \% \mathrm{Cl} 2.12$ to 2.24 and odds ratio of non USA based studies was 2.31 and $95 \% \mathrm{Cl} 1.73$ to 3.09 whereas combined USA and non USA studies odd ratio was 2.6 and $95 \% \mathrm{Cl} 2.20$ to 3.22 . Findings concluded that bully victims had the increased risk of suicidal ideation.
\end{abstract}

Bang J Psychiatry 2015;29(1):35-40

\section{Introduction}

Bullying can be defined as an aggressive act that is carried out by a group or an individual repeatedly and over time against a victim who cannot easily defend himself or herself. ${ }^{1}$ Scientific report indicates that bullying can lead to serious mental and physical sequelae. This is in sharp contrast to the common belief that school bullying is a benign and "normal" part of the child and/ or adolescent experience. Victimized children are reported to have a myriad of clinical problems including bed wetting, sleep difficulties, anxiety, depression, school phobia, feelings of insecurity and unhappiness at school; they may also have low self- esteem, loneliness, isolation and somatic symptoms. ${ }^{2-9}$ In contrast, perpetrators of bullying reported to have more depression and are more likely to be involved with antisocial behaviors and legal problems later in adulthood. ${ }^{2}$ Four main types bullying are distinguished: physical (e.g., assault), verbal (e.g., threats), relational (e.g., social exclusion) and indirect (e.g., spreading rumors). ${ }^{10}$ With the increased use of internet and mobile phones, a new form of bullying has emerged, often labeled 'cyber bullying. ${ }^{10-14}$ In cyber bullying, aggression occurs via electronic forms of contact. ${ }^{13}$ Increased exposure to the online environment has contributed to a heightened appreciation of the potential negative impact of cyber bullying. ${ }^{14}$ Recent cross-sectional studies have shown an association between cyber bullying victimization and mental health problems, and even between cyber bullying victimization and suicide. ${ }^{11,13,15,16}$ The few available longitudinal studies examining the relationship between traditional bullying and mental health problems or suicide (ideation) show that being a victim of traditional bullying increases the risk of developing mental health problems and committing suicide later in life. ${ }^{13,17-23}$ This review process focused on studies published between 2010 and 2015. However, some international data are included from certain notable studies, especially those that address narrower subtopics or notably contribute to theoretical or conceptual conversations. This meta analysis sought to first establish common reference points among different bodies of research, using primary studies along with meta-analyses that aggregate and analyze other research findings to address large-scale or generalizable trends. At times,especially when comparing research definitions or changes in the field over time, the review draws on reviews or book chapters to provide summaries of 
themes and definitions. The document's is built by five researcher and make a consensus that present important research findings. Finally we aimed to see the association of bullying with suicidal ideation in School children and adolescence.

\section{Materials and methods}

This is a meta analytic study. Total 21 studies included purposively with total sample size 219,929 . We included those cross sectional studies that were conducted in the years 2010 to 2015 and the studies that had measured the suicidal ideation following bully victimization were included. Multiple searched method was used to identify the studies. Endnote soft ware were used as a data bases. We also used Pubmed and Google scholar to identify our included studies. Terms used to include studies are 'bullying 'cyber bullying' 'traditional bullying' suicide and bullying 'suicidal ideation. Initially 398 studies were included and finally 21 studies met our inclusion crieteria. Bullying was assessed based on CDCs uniform definition of bullying, several key components ${ }^{1}$ and behavior should be considered when assessing bullying behavior. We coded those studies with bullying measurement and suicidality. Bullying measurement strategies are: 1. how behaviors were described by the authors was it called bullying 2. participants were given definition of bullying 3. how bullying assess through the definition provided to the students -have you bullied and 4. realibility of the bullying. Those studies assessed the suicidalty on the basis of following, such as- i. how was suicidality assessed in the study e.g two or more questions measuring factors associated with suicide such as internalization depression etc that were then summed into suicidality measure, yes/no question directly assessing suicidal thought or behaviors ii. was previously published suicidality scale/instrument used iii. what is the stated reliability for the suicidality instrument? iv. which component of suicidality are asses the study and v. who was the reporter or whatever assessment of suicidality was used e.g self report parent reporter. In this study we assessed one effect size, suicidal ideation by using the predictor bullying victimization between the USA based studies and non USA based studies. Inverse weighted effect size was measured and we used random effect model. Review manager (Revman 5.3) and software for comprehensive meta-analysis, CMA (free trial for 30 days) were used for measuring (log) odd ratio and sampling error and thus constructing the forest plot, which measured the odd ratio of individual study and $95 \% \mathrm{Cl}$ and it also measure pooled odd ratio and pooled $95 \% \mathrm{Cl}$.

\section{Results}

In this meta analysis of 21 studies, USA and non USA based studies from the primarily selected studies were analyzed (Table 1). An inverse weighted average effect size was measured for each study ( Figure 1, 2, 3). Most weighted study depends on more sample size (Figure 1, 2, 3 and Table 1). Study characteristics

Table 1: characteristic of the included USA and non USA studies

\begin{tabular}{|c|c|c|c|}
\hline Authors, Year & Sample size & Mean Age (MA) Range/Grade (G) & Country \\
\hline Bauman $2013^{24}$ & 1491 & G-9-12 & USA \\
\hline Bonanno $2010^{25}$ & 399 & MA 14.2 & CANADA \\
\hline Cheng $2010^{26}$ & 9015 & $13-15$ years & CHINA \\
\hline Cui $2010^{27}$ & 8778 & $11-17$ years & CHINA \\
\hline Espilage $2013^{28}$ & 661 & 10-13years & USA \\
\hline Gower 201329 & 128681 & $11-17$ years & USA \\
\hline Holt $2013^{30}$ & 3096 & NA & SINGAPURE \\
\hline Hay $2010^{31}$ & 426 & 10-21years & USA \\
\hline Heinbron $2010^{32}$ & 493 & 11-14years & USA \\
\hline Henry2013 33 & 2936 & G-6 & USA \\
\hline Hepburn2012 34 & 1838 & G -9 & USA \\
\hline Kessel $2012^{35}$ & 20406 & G-9 & USA \\
\hline Kowalski2013 36 & 931 & $11-19$ years & USA \\
\hline Mark $2013^{37}$ & 4954 & $14-17$ years & ESTONIA \\
\hline Patric $2013^{38}$ & 26523 & G-8 & USA \\
\hline Rivers s $2013^{39}$ & 1592 & $12-16$ & UK \\
\hline Pranjic $2010^{40}$ & 290 & MA 17 & BOSNIA \\
\hline Romero $2013^{41}$ & 650 & $14-18$ & USA \\
\hline Skapinaskis $2011^{42}$ & 2431 & $16-18$ & GREECE \\
\hline Turner $2013^{43}$ & 1874 & $11-18$ & USA \\
\hline Undheim $2013^{44}$ & 2464 & $12-15$ & NORWAY \\
\hline
\end{tabular}


and country of the conducted study was described in Table 1. Our main result is described by the forest plot. Pooling of data of the 21 cross sectional studies showed odd ratio was 2.18 for USA based studies (Figure 2 ) and 2.31 of non USA based studies (Figure 3 ) and $95 \% \mathrm{Cl} 2.12$ to 2.24 and 1.73 to 3.09 respectively and combined USA and non USA studies odd 2.66 and 95\% Cl 2.2 to 3.22 (Fig 1). Though both group of studies have substantially heterogeneity $\mathrm{I}^{2} 95 \%$ and $86 \%$ respectively (Figure 2,3 ) but overall test effect were significant $p<0.00001(Z=54.89 \mathrm{df}=11$ for USA based studies and $Z=5.66$ and $d f=8$ in non USA studies).

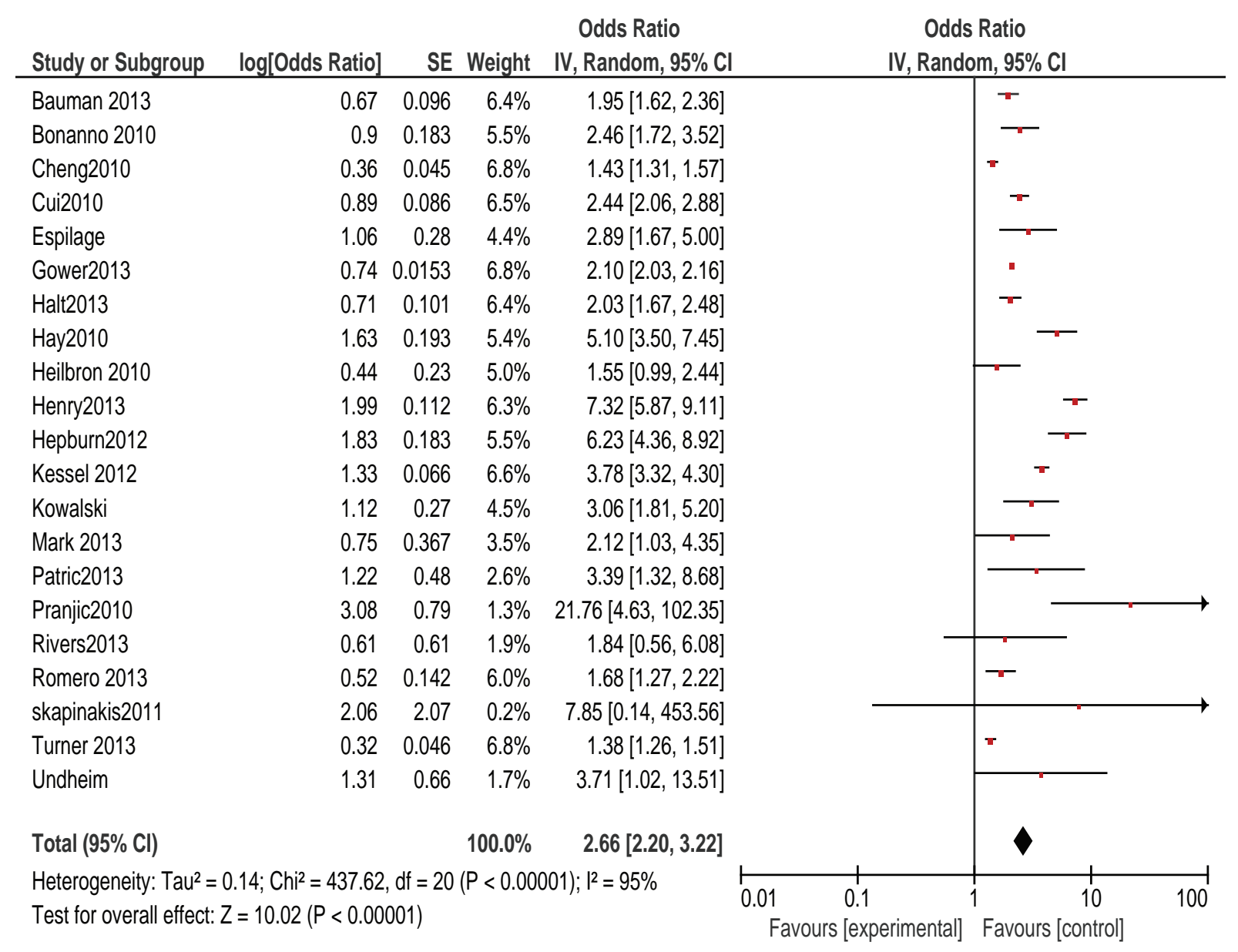

Figure 1: Forest plot for Bully victimization and suicidal ideation combined USA studies and non USA studies.

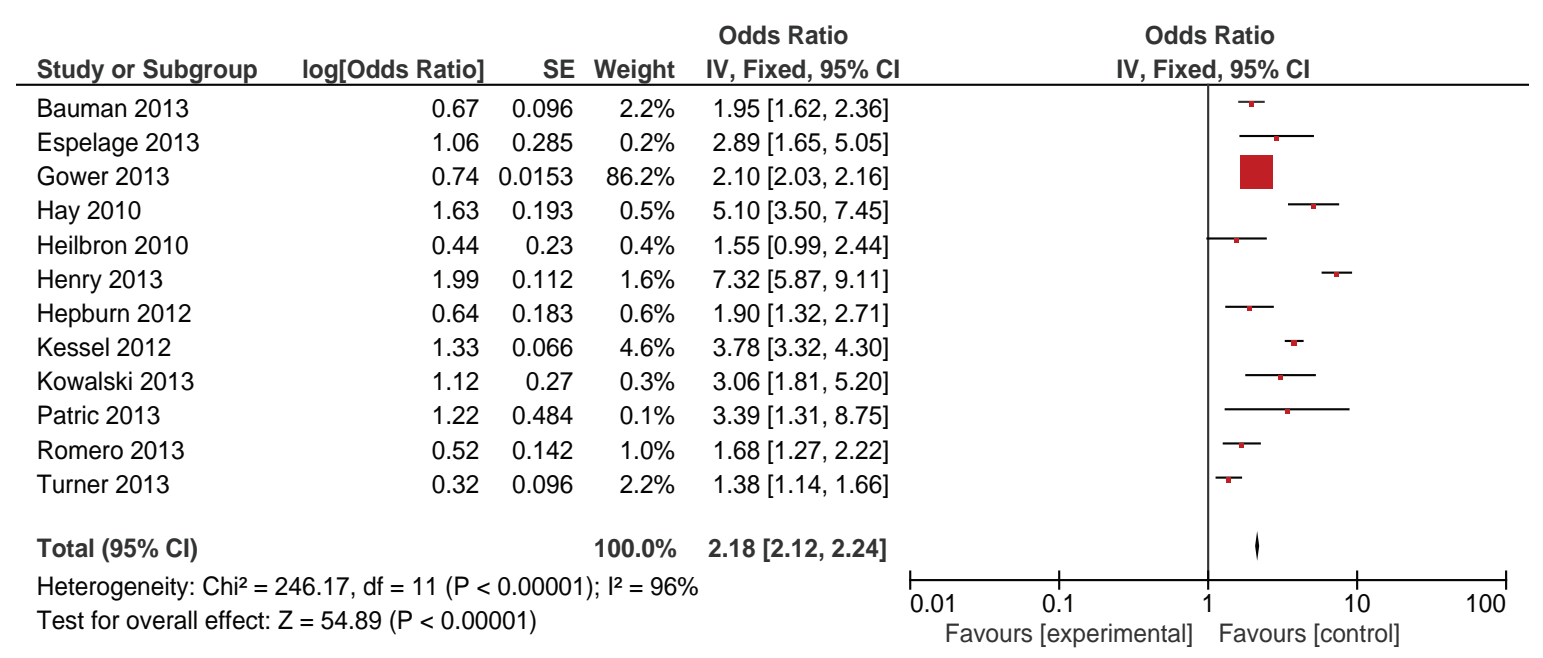

Figure 2: Forest plot of suicidal ideation and bully victimization in USA studies 


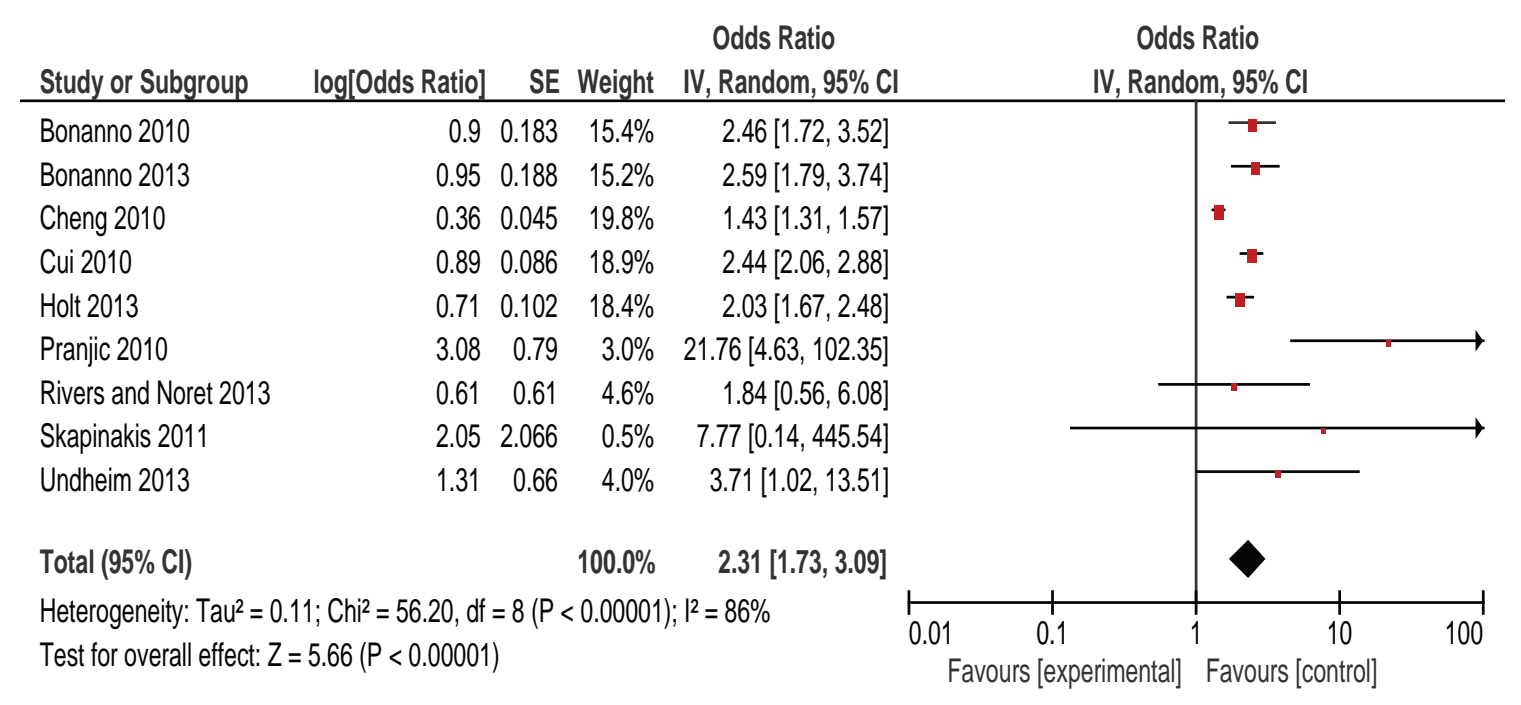

Figure 3: Forest plot of suicidal ideation and bully victimization in non USA studies

\section{Discussion}

As we know from extant literature that prevalence estimates of bullying ${ }^{45}$ and suicidality vary by countries. ${ }^{46}$ Although it is not understood why country moderates these associations, we do know that general perceptions of and responses to bullying are country-specific. Thus, country differences may be in part attributable to differences in countries' approaches to preventing bullying. There is no such type of study in our country even in the subcontinent, so exact picture can not be predicted in our country.

The aim of this meta analysis to see the association between bully victimization and suicidal ideation. Though majority of the studies were USA based but a few studies were conducted outside the USA. We combined both USA studies and non USA studies. We find significant association between bully victimization and suicidal ideation pooled odds ratio is 2.66 and $95 \% \mathrm{Cl} 2.20$ to 3.26 which signifies that there is increase risk of suicidal ideation in bully victims $120 \%$ to $226 \%$ this is alarming for western countries. Similar studies was done by Holt et al find the similar result though this study included all those studies from 2007 to 2013 and they also included several factors like gender and urban and rural area and geographical factors . But we only included bully victimization and assessed the only outcome suicidal ideation and we did not consider the association of gender and geographical area . As we don't find any published data from our country and from the subcontinent, we are not able to include study from our country in this meta analysis. Our study has some limitation including heterogeneity in the included studies and regression meta analysis was not done and our study has some strength that we included recent studies and and we have done sub group analysis by USA and non USA studies.

\section{Conclusion}

This meta analysis concluded that bully victims have increased risk of suicidal ideation both USA based studies and non USA based studies and combined studies. As there is no such type of study conducted in our country, we don't know the exact scenario of our country. Our study finding recommended that large sample study should be conducted in our country.

References

1. Olweus D. Bullying at school: knowledge base and an effective intervention program. Ann N Y Acad Sci 1996;794:265-76.

2. Boulton MJ, Underwood K. Bully/victim problems among middle school children. Br J Educ Psychol 1992;62:73-87.

3. Boulton MJ, Smith PK. Bully/victim problems in middleschool children: stability, self-perceived competence, peer rejection and peer acceptance. $\mathrm{Br} J$ Dev Psychol 1994;12:315-29.

4. Byrne B. Bullies and victims in a school setting with reference to some Dublin schools. Ir J Psychol 1994;15:574-86.

5. Rigby K, Slee P. Dimensions of interpersonal relation among Australian children and implications for psychological wellbeing. J Soc Psychol 1993;133:33-42.

6. Rigby K. The relationship between reported health and involvement in bully/victim problems at school among male and female secondary school children. J Health Psychol 1998;3:465-76.

7. Salmon G, James A, Smith DM. Bullying in schools: self reported anxiety, depression, and self esteem in secondary school children. BMJ 1996;317:924-5.

8. Slee PT. Situational and interpersonal correlates of anxiety associated with peer victimisation. Child Psychiatry Hum Dev 1994;25:97-107.

9. Williams K, Chambers M, Logan S, Robinson D. Association of common health symptoms with bullying in primary school children. BMJ 1996;313:17-9. 
10. Smith PK, Mahdavi J, Carvalho M, Fisher S, Russell S. Cyberbullying: its nature and impact in secondary school pupils. J Child Psychol Psychiatry 2008;49:376-85.

11. Suzuki K, Asaga R, Sourander A, Hoven CW, Mandell D. Cyberbullying and adolescent mental health. Int J Adolesc Med Health 2012;24:27-35.

12. Raskauskas J, Stoltz AD. Involvement in traditional and electronic bullying among adolescents. Dev Psychol 2007;43:564-75.

13. Brunstein KA, Sourander A, Gould M. The association of suicide and bullying in childhood to young adulthood: a review of cross-sectional and longitudinal research findings. Can J Psychiatry 2010;55:282-8.

14. Ybarra ML, Mitchell KJ, Espelage DL. Comparisons of bully and unwanted sexual experiences online and offline among a national sample of youth. In: Ozdemir O, editor. Complementary pediatrics. $3^{\text {rd }}$ ed. Croatia: 2012. p. 203-10.

15. Bonanno RA, Hymel S. Cyber bullying and internalizing difficulties: above and beyond the impact of traditional forms of bullying. J Youth Adolesc 2013;42(5):685-97.

16. Schneider SK, O'Donnell L, Stueve A, Coulter RW. Cyberbullying, school bullying, and psychological distress: a regional census of high school students. Am J Public Health 2012;102:171-7.

17. Schultze KA, Jakel A, Schultze M, Scheithauer H. Emotional and behavioural problems in the context of cyberbullying: a longitudinal study among German adolescents. Emo Behav \& Diffict 2012;17:329-45.

18. Reijntjes A, Kamphuis JH, Prinzie P, Telch MJ. Peer victimization and internalizing problems in children: a metaanalysis of longitudinal studies. Child Abuse Negl 2010;34:244-52.

19. Fisher HL, Moffitt TE, Houts RM, Belsky DW, Arseneault L. Bullying victimisation and risk of self harm in early adolescence: longitudinal cohort study. BMJ 2012;344: e2683.

20. Copeland WE, Wolke D, Angold A, Costello EJ. Adult Psychiatric Outcomes of Bullying and Being Bullied by Peers in Childhood and Adolescence. JAMA Psychiatry 2013;1-8.

21. Schreier A, Wolke D, Thomas K, Horwood J, Hollis C. Prospective study of peer victimization in childhood and psychotic symptoms in a nonclinical population at age 12 years. Arch Gen Psychiatry 2009;66:527-36.

22. Heikkila HK, Vaananen J, Helminen M, Frojd S, Marttunen M. Involvement in bullying and suicidal ideation in middle adolescence: a 2-year follow-up study. Eur Child Adolesc Psychiatry 2013;22:95-102.

23. Lereya ST, Winsper C, Heron J, Lewis G, Gunnell D. Being bullied during childhood and the prospective pathways to self-harm in late adolescence. J Am Acad Child Adolesc Psychiatry 2013;52:608-18 .

24. Bauman S, Toomey RB, Walker JL. Associations among bullying, cyberbullying, and suicide in high school students. J Adolesc 2013;36(2):341-50.
25. Bonanno RA, Hymel S. Beyond hurt feelings: investigating why some victims of bullying are at greater risk for suicidal ideation. Merrill-Palmer Q 2010;56(3):420-40.

26. Cheng $\mathrm{Y}$, Newman IM, Qu M. Being bullied and psychosocial adjustment among middle school students in China. J Sch Health 2010;80(4):193-9.

27. Cui S, Cheng Y, Xu Z, Chen D, Wang Y. Peer relationships and suicide ideation and attempts among Chinese adolescents. Child Care Health Dev 2011;37(5):692-792.

28. Espelage DL, Holt MK. Suicidal ideation and school bullying experience after controllingfor depression and delinquency. $\mathrm{J}$ adolesc Health 2013;53(1suppl):s27-S31.

29. Gower AL, Borowsky IW. Associations between frequency of bullying involvement and adjustment in adolescence. Acad Pediatr 2013;13(3):214-21.

30. Holt TJ, Chee G, Ng E, Bosslerb A.Exploring the consequences of bullying victimization in a sample of Singapur youth. Int Crim Justice Rev 2013;23:25-40.

31. Hay C, Meldrum R. Bullying victimization and adolescent self-harm: testing hypotheses from general strain theory. J Youth Adolesc 2010;39(5):446-59.

32. Heilbron N, Prinstein M. Adolescent peer victimization, peer status, suicidal idand nonsuicidal self-injury: examining concurrent and longitudinal associations. Merrill-Palmer Q 2010;56(3):388.

33. Henry KL, Lovegrove PJ, Steger MF, Chen PY, Cigularov $\mathrm{KP}$, Tomazic RG. The potential role of meaning in life in the relationship between bullying victimization and suicidal ideation. J Youth Adolesc 2014;43(2):221-32.

34. Hepburn L, Azrael D, Molnar B, Miller M.Bullying and suicidal behaviors among urban high school youth. J Adolesc Health 2012;51(1):93-5

35. Schneider SK, O'Donnell L, Stueve A, Coulter RWS. Cyberbullying, school bullying, and psychological distress: a regional census of high school students. Am J Public Health 2012; 102(1):171-7.

36. Kowalski RM, Limber SP. Electronic bullying among middle school students. J Adolesc Health 2007;41:S22-S30.

37. Mark L, Samm A, Tooding L-M. Suicidal ideation, risk factors, and communication with parents. An HBSC study on school children in Estonia, Lithuania, and Luxembourg. Crisis 2013;34(1):3-12.

38. Patrick DL, Bell JF, Huang JY, Lazarakis NC, Edwards TC. Bullying and quality of life in youths perceived as gay, lesbian, or bisexual in Washington State, 2010. Am J Public Health 2013;103(7):1255-61.

39. Pranjic N, Bajraktarevic A. Depression and suicide ideation among secondary school adolescents involved in school bullying. Prim Health Care Res Dev 2010;11(4):349-62.

40. Rivers I, Noret N. Potential suicide ideation and its association with observing bullying at school. J Adolesc Health 2013;53:S32-S36.

41. Romero AJ, Wiggs $C B$, Valencia $C$, Bauman S. Latina teen suicide and bullying. Hisp J Behav Sci 2013;35(2):159-73.

42. Skapinakis P, Bellos $S$, Gkatsa T. The association between bullying and early stages of suicidal ideation in late adolescents in Greece. BMC Psychiatry 2011;11:22. 
43. Turner MG, Exum ML, Brame R, Holt TJ. Bullying victimization and adolescent mental health: general and typological effects across sex. J Crim Justice 2013;42:53-9.

44. Undheim AM, Sund AM. Involvement in bullying as predictor of suicidal ideation among 12- to 15-year-old Norwegian adolescents. Eur Child Adolesc Psychiatry 2013;22(6): 357-65.
45. World Health Organization. Suicide Rates and Absolute Numbers of Suicide by Country.[online]. [Cited 2016 August 20]; Available from URL : http://www.who.int/mental_health/ prevention /suicide/suicide prevent

46. Fleming LC, Jacobsen KH. Bullying among middle-school students and middle income countries. Health Promot Int 2010;25(1):73-84. 